\title{
Magnitude and Factors Affecting Out-of-Pocket Medical Expenditure among Outpatients in ST.Paul Hospital Millennium College, Addis Ababa, Ethiopia
}

\author{
Amelewerk Alemu ${ }^{1}$, Mesfin Aklilu², Wogayehu Tadele ${ }^{1}$ \\ ${ }^{1}$ Health Economics Department, Ethiopian Public Health Institute, Addis Ababa, Ethiopia \\ ${ }^{2}$ Human Resource for Health Management Department, Ethiopian Public Health Institute, Addis Ababa, Ethiopia \\ Email address: \\ amealemu@yahoo.com (A. Alemu),mesfinaklilu@yahoo.com (M. Aklilu), wentadele12@gmail.com (W. Tadele) \\ To cite this article: \\ Amelewerk Alemu, Mesfin Aklilu, Wogayehu Tadele. Magnitude and Factors Affecting Out-of-Pocket Medical Expenditure among \\ Outpatients in ST.Paul Hospital Millennium College, Addis Ababa, Ethiopia. International Journal of Health Economics and Policy. \\ Vol. 4, No. 1, 2019, pp. 29-34. doi: 10.11648/j.hep.20190401.14
}

Received: February 1, 2019; Accepted: March 18, 2019; Published: April 12, 2019

\begin{abstract}
The Objectives of the study is to assess the magnitude and factor that affect out-of pocket medical expenditure among outpatients department in St Paul's hospital Millennium College, Addis Ababa, Ethiopia. An Institution-based crosssectional study in quantitative method was conducted among outpatient services. The required sample size is determined by single population and double population proportion formula. The final sample size was 422 . A descriptive statistical analysis, binary and multivariable logistic regression model was used to describe the findings. Gender, marital status, educational status, occupation, family size, total income was statistically associated with TOOPME at $\mathrm{Sig}<0.2$. Statistically associated with TOOPME In multivariate analysis were marital status ( $\mathrm{B}=.197$; $\mathrm{CI} 95 \% 190.2-585$; sig .000), Occupation status $(\mathrm{B}=-.174$; $\mathrm{CI}$ 95\%-180-39.6; sig .002), family size ( $\mathrm{B}=.229$; $\mathrm{CI} 95 \% 58-150$; sig .000), and total income ( $\mathrm{B}=.305$; CI 95\%10Table: 1 9-227; sig .000). The financing system of health care should be based on the principle of cost sharing so that there will be resource pooling among the poor and the rich. The financing mechanism should also move into prepayment schemes or insurance to protect the poor from unanticipated health care costs.
\end{abstract}

Keywords: Out-of-Pocket Expenditure, Catastrophic Health Expenditures, Health Care Seekers

\section{Introduction}

Out-of-Pocket medical expenditure (OOPME) is defined as the direct outlay by households including gratitude's and in kind payments to health practitioners and pharmaceutical suppliers and the purchases of goods and services whose main intent is to contribute to the restoration on the enhancement of the health status of individuals and population groups [1]. Researchers at the World Health Organization (WHO) propose that health spending becomes catastrophic when out-of-pocket health spending exceeds 15$20 \%$ of the total health expenditure level [2]. The level of OOP and their distribution have great impact on overall health system performance. When a system relies heavily on OOP, the payments required to access health care in relation to income can be high enough to result in financial catastrophe for individuals or households [3].
Due to high health expenditures, each year nearly 44 million households worldwide have to pay catastrophic healthcare expenditures. Almost 25 million of households or, in other words more than 100 million people, are pushed below the poverty line due to catastrophic expenditures [4]. Comparing OOP expenditure in the public and private sectors, "cashless" hospitalizations were more common in public than in private facilities and those going to the private sector were more likely to incur OOP expenditure [5].

Research has shown important differentials in financial access between men and women. For example, "women incur more out-of pocket expenditure than men", "paying for health care and other reproductive health services places a high financial burden on women" and "out-of-pocket expenditure may prevent more women than men from utilizing essential health services" [2]. According to the World Health Survey $27 \%$ of households in Ethiopia faced 
financial catastrophe - defined as OOP payments of more than $150 \%$ of household's consumption expenditure [6].

High OOP health expenditures have a serious impact on vulnerable people who subsequently experience debt, income loss and catastrophic health expenditures [7]. Rapid population ageing has intensified concerns about the extent to which geriatric health spending can become catastrophic, Reproductive health (RH) expenditure constituted more than $10-12 \%$ of the total expenditure on health. Out-of-pocket payment for RH was minimal, and government is the key source of RH spending (5). However, RH expenditures in 2007/2008 in Ethiopia was about 13\% (ETB 1,411,728,484) of the national health expenditure. The per capita expenditure for the relevant group, women age $15-49$ years was only US\$8. The government managed the largest share $(45 \%)$ of $\mathrm{RH}$ expenditures, the private sector managed $33 \%$ of $\mathrm{RH}$ resources, and the rest of the world managed $22 \%$ of RH resources [8].

Furthermore, later-life health studies on the Nigerian elderly suggest that elderly groups experience a decline in physical and mental capabilities unique to old age, which increases dependence for health care finance [2]. As it has been said, the main factor for women discouraged to utilize RH services is related to getting money for treatment, showing that expenditure is one of the main factors and particularly a concern since private expenses are paid OOP [8]. Knowledge about the magnitude and Factors Affecting OOPME among outpatient service is vital from a health policy perspective, to inform the design of interventions or system changes that ensure accessible and financially protective health services to vulnerable people. Therefore assessing financial burden especially on female and elderly people done in St Paul's hospital millennium college is useful for decision maker to create strategy on financial protection for these groups of population.

\section{Methods}

\subsection{Study Design}

An Institution-based cross-sectional study in quantitative method was conducted among outpatient services, in St Paul's hospital millennium college.

\subsection{Study Area}

The study was conducted in Addis Ababa, which is the capital city of Ethiopia and most of the federal government are located in here; additionally health service implemented and actively practice. The St Paul's hospital millennium college is the second largest hospital in Ethiopia; it currently has 310 beds with an annually average of 200,000 patient and catchment population of more than 5 million. The study will be based on primary and secondary data conducted on outpatient in St Paul's hospital millennium college. It will implement from March $1^{\text {st }}, 2018$.

\subsection{Study Population and Sample Size}

Adult Patients who was attending an outpatient services, in St Paul's hospital millennium college fromMarch ${ }^{\text {st }}$ to 30 and fulfill the inclusion criteria. The required sample size for the first and second objectives of this study was determined by single population and double population proportion formula respectively. The sample size was determined by using single proportion formula with the following assumptions; Confidence level (CI) -95, Proportion (P) -50 \% Marginal of error (d) $-5 \%$, Sample size is computed based on single proportion formula assuming $\mathrm{p}=\mathrm{q}=0.5$ since there was no research conducted on this topic in Ethiopia

$$
Z_{\frac{\alpha}{2}}^{2} \frac{p(1-p)}{d^{2}}, n=1.96^{2} \frac{0.50(0.50)}{0.05^{2}}=384.16
$$

So with adjustment for non-response (10\% contingency), $\mathrm{n}=(384+38)$, the final sample size was 422 .

\subsection{Sampling Procedure}

Three departments were selected purposefully which are medical, surgical and gynaecology outpatient (OPD). The study participant was identified by systematic random sampling method. Depending on sampling interval patients coming to OPD was enrolled in the study until the required sample size was obtained from selected OPD.

\subsection{Data Collection Tools and Procedures}

Data was collected by interviewed using structured questionnaire. The questionnaire consists of sociodemographic variables (age, sex, marital status, residence, monthly income, educational status and occupation) and contained questions that were elicit information on magnitude and factors affecting OOPME out patients. The questionnaire was first be prepared in English and translated to Amharic, since patients may not able to understand English questionnaires. Pretesting of the questionnaire was done internally at St Paul hospital. The pretesting was done to assess the applicability of the questionnaire tool internally. Orientation was given for study participants on the tools to be used and purpose of the study.

\subsection{Data Quality Control}

The quality of data was assured by proper designing and pre-testing of the questionnaires on selected patient in St Paul hospital. Every time after data collection, questionnaires was reviewed and checked for completeness by the principal investigator. Moreover, the collected data was clean, coded and entered to EPI Info version7.0.

\subsection{Data Analysis}

Data was exported to SPSS version 20 statistical package, and then analyzed. A descriptive statistical analysis was used to describe the findings. Descriptive summary using frequencies, percentages, bar chart, central tendency was used for socio-demographic and bar chart for relevant variables. Data was compiled and analyzed using bi-variate multiple linear regression models. Variables, which have pvalue less than 0.2 bi-variate analyses, was taken in to multivariable analysis. A p-value $<0.05$ were considered to 
declare a statistically significant association with dependent and selected independent variables. The results was presented in text and tables based on the type of data

\section{Results}

\subsection{Socio Demographic Character}

Total population of the respondents was 422 and results indicated that $35.2 \%$ of the respondents were male whereas $64 \%$ of the respondents were female. Majority of the respondents stated that they were between $31-45$ years old and $16.5 \%$ and $30.5 \%$ of the total respondents stated that they were between 25-30 years and 46-60 years old respectively. Whereas $15.6 \%$ respondents were above the age of 60 . The study also sought to collect the level of education of respondents. The results indicated that $9 \%$ of the respondents had higher education \&above followed by $48 \%$ who were Secondary level. $20 \%$ of the respondents were in primary level where as $11 \%$ of respondents were literate and illiterate respectively. See table: 1 below

Table 1. Socio demographic Character.

\begin{tabular}{llll}
\hline & & Frequency & Percent \\
\hline \multirow{3}{*}{ Gender } & Male & 149 & 35.2 \\
& Female & 273 & 64.5 \\
\multirow{5}{*}{ Age } & $<30$ & 70 & 16.5 \\
& $31-45$ & 147 & 34.8 \\
& $46-60$ & 129 & 30.5 \\
\multirow{5}{*}{ Education } & L60 & 66 & 15.6 \\
& Illiterate & 47 & 11.1 \\
& Piterate & 47 & 11.1 \\
T income & Secondary School & 85 & 20.1 \\
& higher education \& above & 38 & 48.0 \\
\hline
\end{tabular}

\begin{tabular}{lll}
\hline & Frequency & Percent \\
\hline$<2000$ & 69 & 16.3 \\
$2001-4000$ & 147 & 34.8 \\
$4001-6000$ & 161 & 38.1 \\
$>6000$ & 45 & 10.6 \\
\hline
\end{tabular}

\subsection{Magnitude of Total Out-of Pocket Medical Expenditure of Respondents}

The study collected the monthly income earned by 422 respondents. It was established from the descriptive of Total statistics results that maximum and minimum Total Out-of Pocket medical expenditure of the respondents was 7966Birr and 37 Birr respectively. Average monthly Total Out-of Pocket medical expenditure by the respondents was 610 Birr with a standard deviation of 1043 Birr. See Table 2 below.

Table 2. Magnitude of Total Out-of Pocket medical expenditure.

\begin{tabular}{ll}
\hline Mean & 1047.73 \\
Median & 610.00 \\
Std. Deviation & 1043.82 \\
Minimum & 37.00 \\
Maximum & 7966.00 \\
\hline
\end{tabular}

\subsection{Gender Status of Respondents Against TOOPME}

Gender status against Total Out-of Pocket medical expenditure revealed that the highest number of female respondents during one month of study session were belonged to 500-1000Birr (37.4\%), and the lowest respondent were belong to 1501-2000Birr spending group $(5.5 \%)$, On the other hand, the highest number of male respondents against Total Out-of Pocket medical expenditure were belonged to less than 500 Birr spending group (33.6) and the lowest respondents were belonged to above 2000 Birr spending group (8.7\%). See Figure 2 below.

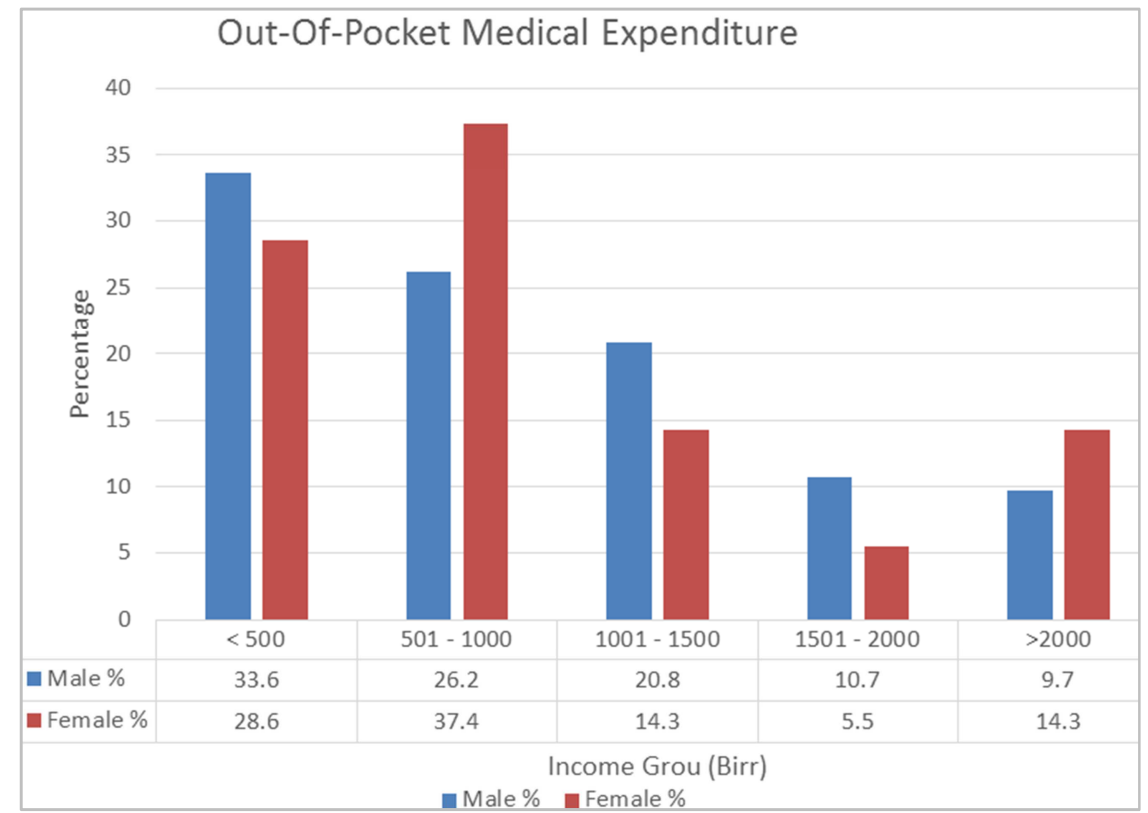

Figure 1. Gender status of respondents against TOOPME. 


\subsection{TOOPME Versus Income Group}

Among total income group against TOOPME, 24\% and $11.5 \%$ of respondents that belonged to less than 2000 Birr house hold income group spend less than 500 Birr and greater than 2000 Birr respectively during one month of study session. Similarly $39.8 \%$ and $25 \%$ of respondents that belonged to 2001 - 4000 Birr household income group spend less than 500 Birr and greater than 2000 Birr during one month of study session respectively. See Figure 2 and 3 below.

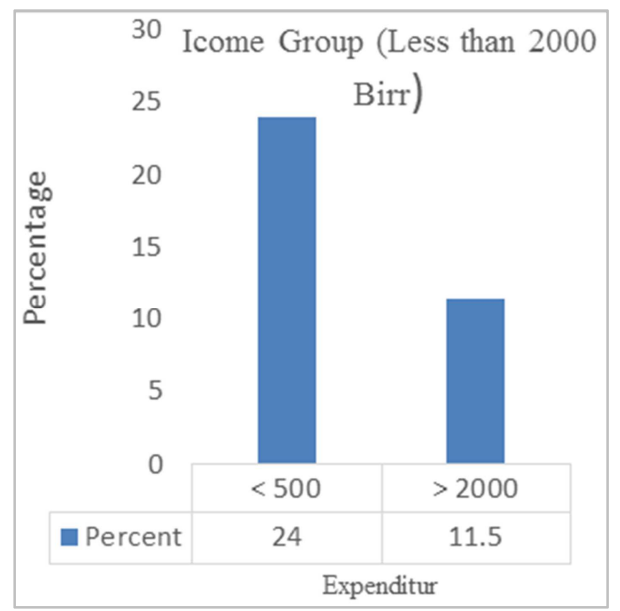

Figure 2. Relationships between TOOPME and Income Group (less than 2000 birr).

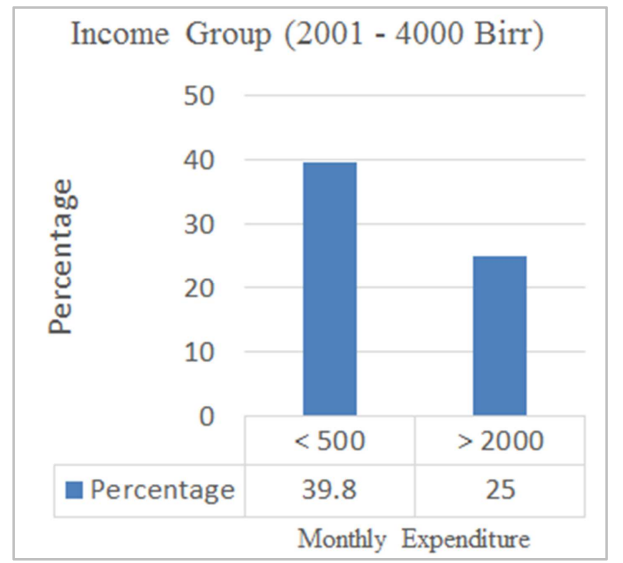

Figure 3. Relationships between TOOPME and Income Group (20001 4000 birr).

Regarding house hold income group, $29.7 \%$ and $32.7 \%$ of respondents that belonged to $40001-6000$ birr income spend less than 500 Birr and greater than 2000 Birr respectively during one month of study session. Similarly $6.3 \%$ and $38 \%$ of respondents that belonged to greater than 6000 Birr income group spend less than 500 Birr and greater than 2000 Birr during one month of study session for health care respectively. See Figure 4 and 5 below.

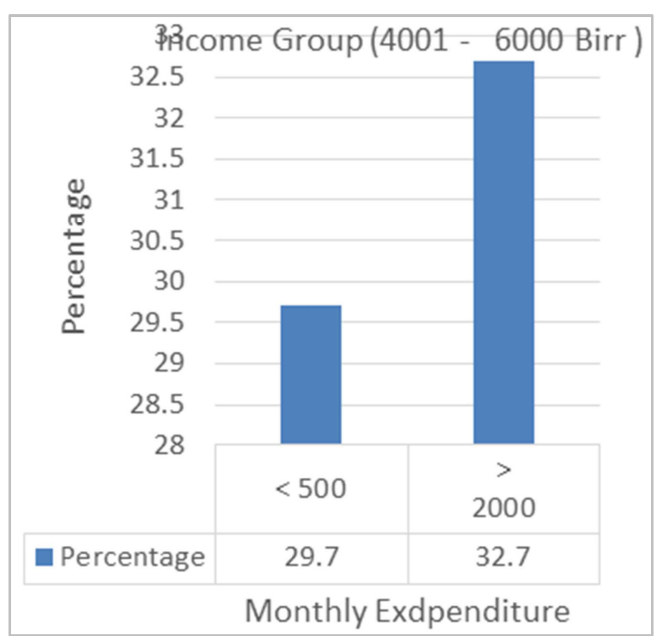

Figure 4. Relationships between TOOPME and Income Group (4001 - 6000 birr).

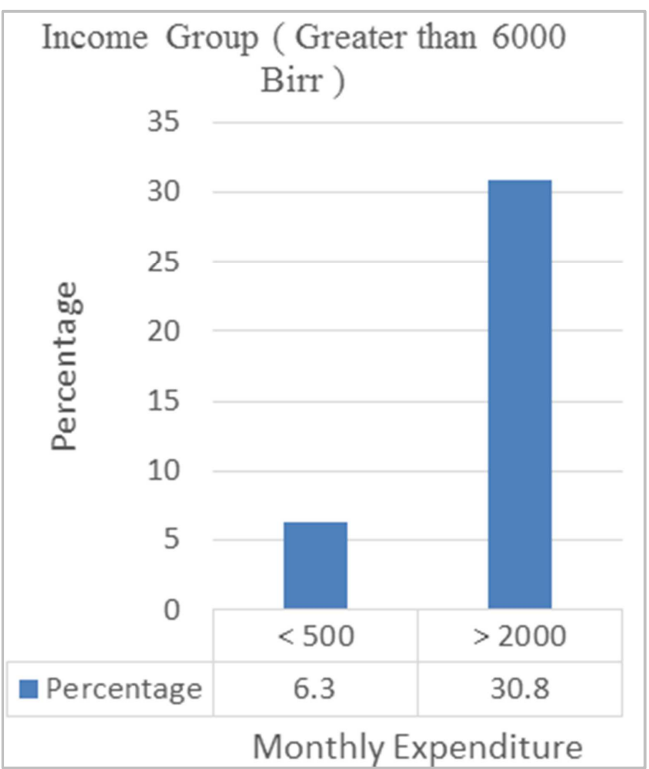

Figure 5. Relationships between TOOPME and Income Group (Greater than 6000 birr).

\subsection{Factors Associated with TOOPME}

In order to identify the associated factors with gender, marital status, educational status, occupation, family size, total income were statistically associated with TOOPME at $\mathrm{Sig}<0.2$ in other variables age and resident had Sig greater than 0.2 , So didn't perform in multivariate analysis. In multivariate analysis were statistically associated with TOOPME marital status $(B=.197$; CI 95\%190.2-585; sig .000), occupation status $(\mathrm{B}=-.174$; CI 95\%-180-39.6; sig .002), family size ( $\mathrm{B}=.229$; CI $95 \% 58-150$; sig .000), total income $(\mathrm{B}=. .305$; $\mathrm{CI} 95 \% 109-227$; sig .000). However gender and education were statistically associated with TOOPME. See Figure 7.3 below 
Table 3. Bi-viriate and Multivariate analysis.

\begin{tabular}{|c|c|c|c|c|c|c|c|c|}
\hline \multirow{2}{*}{\multicolumn{2}{|c|}{ Model }} & \multirow{2}{*}{$\begin{array}{l}\text { Standardized } \\
\text { Coefficients B }\end{array}$} & \multirow{2}{*}{ sig } & \multirow{2}{*}{$\begin{array}{l}\text { Un Standardized Coefficients } \\
\text { Beta }\end{array}$} & \multirow{2}{*}{$\begin{array}{l}\text { Standardized } \\
\text { Coefficients B }\end{array}$} & \multirow{2}{*}{ Sig. } & \multicolumn{2}{|c|}{$95.0 \%$ Confidence Interval for B } \\
\hline & & & & & & & \multirow{2}{*}{$\begin{array}{l}\text { Lower Bound } \\
-1429.958\end{array}$} & \multirow{2}{*}{$\begin{array}{l}\text { Upper Bound } \\
214.836\end{array}$} \\
\hline 1 & (Constant) & & & -607.561 & & .147 & & \\
\hline & Gender & .066 & .17 & 57.603 & .026 & .591 & -153.075 & 268.281 \\
\hline & Marital Status & .17 & .001 & 387.738 & .197 & .000 & 190.218 & 585.258 \\
\hline & Education & -1.59 & .001 & -17.787 & -.019 & .722 & -115.996 & 80.421 \\
\hline & Occupation & -0.64 &. .19 & -110.005 & -.174 & .002 & -180.372 & -39.637 \\
\hline & Family Size & .26 & .00 & 103.959 & .229 & .000 & 58.045 & 149.873 \\
\hline & Total income & .04 & .004 & .168 & .305 & .000 & .109 & .227 \\
\hline
\end{tabular}

\section{Discussion}

The main focus of this study was to examine the financial burden of OOP among St Paul hospital OPD health service seekers. In this research the most respondents were females, middle age and middle level education groups. Globally the total amount of expenditure on health is increasing as countries are becoming richer [9]. For There is increasing evidence that out-of-pocket expenditures act as a financial barrier to accessing health care, and are a source of catastrophic expenditures and impoverishment [10]. Now a days the role of private health care providers has sparked controversial debates in low-and middle income countries [11]. OOP payments in low income countries are very regressive as determined by in other settings [12]. Accordingly Individuals with comparatively low income face a higher burden of OOP payments than individuals with higher income [13]. Based on the results of household's economic status, households with better financial status, face catastrophic health expenditures less than households with worse economic status. The findings of the present study are consistent with the study done in Iran [4]. Similarly it is also supported by the study done in Bangladesh that showed burden of OOP payments were highest among the poor than high income group consumers. Accordingly the lowest income group had lesser Out-of-pocket health expenditure for health services compared with consumers within the higher income group. It has some similarities from a study done in Tanzania in that those with better economic resources, education; enhanced awareness has a tendency towards the need for health care. On the contrary, the poor and those with low literacy level consumers were less likely to use health services [6].

Evidences suggest that Out of pocket payments are the common way of expenditure for health care services in developing countries. These payments have differential impact with respect to health outcomes, health service utilization, and financial burden based on socio-economic status of the population. Under utilization of health services especially by the poor and disadvantaged remains a chronic problem in developing countries even though there is a huge unmet need for health care [14]. Usually out of pocket expenditures result in financial difficulties by households. Moreover the part or all of the costs are borne by other body such as insurance and it will not be catastrophic [8]. However, in this study, all of the expenditures were paid out of pocket and the households are found the poorest quintile. On the other hand, in the absence of financial protection for the poor, small costs are financially disastrous because it will take large proportion of their income. Qualitative findings also indicate that health-seeking behavior differed between men and women [15].

The present study is also supported by Various studies that indicates demographic factors like age, sex, marital status, place of residence, and family wealth influence higher OOP health expenditures [16]. According to the present study, Greater percentage of females had higher Out-of-pocket health expenditures compared with male respondents

\section{Conclusion}

The distribution of out-of-pocket payments across the wealth quintiles shows that households having better socioeconomic status pay more than the low quintiles. It indicates low income group had low quality and quality of health services. In gender status females had high burden of OOP compared to male respondent. Clearly, more attention is needed to reduce financial burden on households among this group. There for extending the national health insurance scheme, expanding the fee waiver system, and maintaining the general subsidy at public health facilities provide coverage for low income group and females people through the proposed special health fund, to encourage enrolment and reduce the risk of catastrophic spending.

\section{Acknowledgements}

First and foremost, I would like to express my deepest gratitude to ACIPH for the necessary knowledge and skill I have acquired to conduct this study and I am indebted to my advisor Dr. Amare Worku for his advice and technical support to make this work a reality.

Again, I am extremely grateful to Dr. Abule Ero and Miss. Kidist Alemayehu who have been there to clear my ambiguities starting from day one.

\section{Conflicts of Interest}

The author(s) declare that they have no competing interests 


\section{References}

[1] Okello NO, Njeru A. Factors Affecting Out-Of-Pocket Medical Expenditure Among Out Patients in Hospitals in Nairobi County. People. 2013;

[2] Adisa O. Investigating determinants of catastrophic health spending among poorly insured Elderly households in urban Nigeria. Int J Equity Health [Internet]. 2015 Sep 15 [cited 2017 /Oct 26]; $14 . \quad$ Available from: https://www.ncbi.nlm.nih.gov/pmc/articles/PMC4570723.

[3] Organization WH. Validity and comparability of out-of-pocket health expenditure from Household surveys: a review of the literature and current survey instruments. 2011;

[4] Moghadam MN, Banshi M, Javar MA, Amiresmaili M, Ganjavi S. Iranian Household Financial Protection against Catastrophic Care Expenditures. Iran J Public Health. 2012 Sep 1; 41(9):62-70.

[5] Nandi S, Schneider H, Dixit P. Hospital utilization and out of pocket expenditure in public and private sectors under the universal government health insurance scheme in Chhattisgarh State, India: Lessons for universal health coverage. Prinja S, editor. PLOS 2017 Nov 17; 12(11): e0187904.

[6] Tolla MT, Norheim OF, Verguet S, Bekele A, Amenu K, Abdisa SG, et al. Out-of-pocket. expenditures for prevention and treatment of cardiovascular disease in general and Health. specialised cardiac hospitals in Addis Ababa, Ethiopia: a cross-sectional cohort study. BMJ Glob 2017 Jun; 2(2): e000280.

[7] Brinda EM, Andrés RA, Enemark U. Correlates of out-of-pocket and catastrophic health expenditures in Tanzania: results from a national household survey. BMC Int Health Hum Rights [Internet]. 2014 Dec [cited 2017 Oct 26]; 14(1). Available from: $\mathrm{http} / / / \mathrm{bmcinthealthhumrights.biomedcentral.com/articles/10.1186}$ /1472-698X-14-5.
[8] Tibebe A, Amarech G, Melesse T, Mariam DH. Examining out of pocket payments for -affordability. Ethiop J Health Dev. 2012; 26(1):251-257. maternal health in rural Ethiopia: paradox of free health care un.

[9] Ke X, Saksena P, Holly A. The Determinants of Data Analysis. 28. Health Expenditure: A Country-Level Panel.

[10] Kimani DN, Mugo MG, Kioko UM. Catastrophic Health Expenditures And Impoverishment In Kenya. Eur Sci J ESJ. 2016 May 30; 12(15):434.

[11] Health services utilization and out-of-pocket expenditure at public and private facilities in low-income countries.pdf.

[12] Jane Chuma, Thomas Maina. Catastrophic health care spending and impoverishment in Kenya. Bio Med Cent. 2012;

[13] Bremer P. Forgone care and financial burden due to out-ofpocket payments within the German health care system. Health Econ Rev [Internet]. 2014 Dec [cited 2019 Jan 28]; 4 (1). Available from: http://www.healtheconomicsreview.com/content/4/1/36.

[14] Pg O. Out-of-pocket payment for health services: constraints and implications for employees in Abakaliki, Ebonyi state, South east Nigeria. 2011; 11(3):5. Government.

[15] Onah MN, Govender V. Out-of-Pocket Payments, Health Care Access and Utilisation in South-Eastern Nigeria: A Gender Perspective. Molyneux S, editor. PLoS ONE. 2014 Apr. 11; 9(4): e93887.

[16] Mahumud RA, Sarker AR, Sultana M, Islam Z, Khan J, Morton A. Distribution and 2017 Determinants of Out-ofpocket Healthcare Expenditures in Bangladesh. J Prev Med Pub Health. Mar 31; 50(2):91-9. 